\title{
Anterior Dental Microwear Texture Analysis of the Krapina Neandertals
}

Kristin L. Krueger

Loyola University Chicago, kkrueger4@luc.edu

Peter S. Ungar

University of Arkansas

Follow this and additional works at: https://ecommons.luc.edu/anthropology_facpubs

Part of the Anthropology Commons

\section{Recommended Citation}

Krueger, KL and PS Ungar. "Anterior Dental Microwear Texture Analysis of the Krapina Neandertals." Central European Journal of Geosciences 4(4), 2012.

This Article is brought to you for free and open access by the Faculty Publications and Other Works by Department at Loyola eCommons. It has been accepted for inclusion in Anthropology: Faculty Publications and Other Works by an authorized administrator of Loyola eCommons. For more information, please contact ecommons@luc.edu. (c) (1) $\Theta \Theta$

This work is licensed under a Creative Commons Attribution-Noncommercial-No Derivative Works 3.0 License. (c) Springer, 2012. 


\title{
Anterior dental microwear texture analysis of the Krapina Neandertals.
}

\author{
Kristin L. Krueger ${ }^{1 *}$, Peter S. Ungar ${ }^{2}$ \\ 1 Department of Anthropology, Loyola University Chicago, Chicago, IL 60660 USA \\ 2 Department of Anthropology, University of Arkansas, Fayetteville, AR 72701 USA
}

Received 13 September 2012; accepted 16 November 2012

\begin{abstract}
Some Neandertal anterior teeth show unusual and excessive gross wear, commonly explained by non-dietary anterior tooth use, or using the anterior dentition as a tool, clamp, or third hand. This alternate use is inferred from aboriginal arctic populations, who used their front teeth in this manner. Here we examine anterior dental microwear textures of the Krapina Neandertals to test this hypothesis and further analyze tooth use in these hominins.

Microwear textures from 17 Krapina Dental People were collected by white-light confocal profilometry using a 100x objective lens. Four adjacent scans were generated, totaling an area of $204 \times 276 \mu \mathrm{m}$, and were analyzed using Toothfrax and SFrax SSFA software packages. The Neandertals were compared to six bioarchaeologi$\mathrm{cal} /$ ethnographic samples with reported variation in diet, abrasive load, and non-dietary anterior tooth use. Results indicate that Krapina anterior teeth lack extreme microwear textures expected of hominins exposed to heavy abrasives or those that regularly generated high stresses associated with intense use of the front teeth as tools. Krapina hominins have microwear attributes in common with Coast Tsimshian, Aleut, and Puye Pueblo samples. Collectively, this suggests that the Krapina Neandertals faced moderate abrasive loads and only periodically used their anterior teeth as tools for non-diet related behaviors.
\end{abstract}

Keywords: Krapina $\cdot$ Neandertal $\cdot$ microwear $\cdot$ anterior teeth $\bullet$ teeth as tools

(c) Versita sp. z o.o.

\section{Introduction}

The unusual pattern of anterior tooth wear found on some noteworthy Neandertal specimens (including mandible $\mathrm{J}$ from Krapina) has been the subject of study and debate for several decades. While some paleoanthropologists suggested it was from the use of the dentition as a

*E-mail: Department of Anthropology, 1032 W. Sheridan Road, Chicago, IL 60660 USA; Email: kkrueger4@luc.edu compensatory mechanism for amputated hands [1], others proposed the wear to result from the excessive mastication of grit-laden foods $[2,3]$. Yet other researchers suggested that this pattern was due to jaw movements associated with the chewing cycle, or that a combination of diet and non-dietary causes were responsible [4-7]. Please refer to [7] for images of the Krapina anterior tooth wear.

The most common explanation for the abnormal anterior tooth wear in some Neandertal individuals involves the "stuff and cut" scenario. According to this idea, Neandertals used their front teeth as a clamp or third hand for grasping items that required processing with tools [8-11]. 
This idea is closely associated with C. Loring Brace, who developed it based on ethnographic reports of Alaskan Eskimo and Canadian and Greenland Inuit groups that used their anterior dentition in this manner, to grasp chunks of meat as they sliced them with a knife $[8,9,11]$. The "stuff and cut" scenario has throughout the decades been expanded to include other types of non-dietary anterior tooth use behaviors found in recent modern human populations, such as animal hide and sinew preparation, basketry tasks, wood softening, and tool production and retouching [12-15].

Indeed, non-dietary anterior tooth use is now considered fundamental in discussions of Neandertal behavioral strategies, regardless of differences in time, space, and environmental context. This is problematic, however, because we cannot assume Neandertal behavior was static - much like modern human foragers, these fossil hominins likely varied in behavior across time, space, and habitat. This variation has yet to be integrated into models of anterior tooth use. The advent of paleoclimatology, refined lithic and faunal assemblage studies, improved absolute and relative dating techniques, and stable isotope analyses allow for the construction of more complex interpretive frameworks. Analyses of Neandertal anterior tooth wear can benefit from these new lines of evidence.

Here we examine anterior dental microwear textures of the Krapina Neandertals as a proxy for anterior tooth use to better understand wear patterns in this sample. The $\mathrm{Ne}-$ andertals from Krapina are extremely well suited for this sort of study not only because the sample represents the largest collection of its kind from a single site, but also because of contextual data available for the accumulations. The Krapina Neandertal sample has been dated to MIS 5e, the last interglacial, and paleoenvironmental reconstructions suggest this area was covered by temperate forest during the Neandertal occupation [16-18]. Further, faunal assemblage analyses on the larger community of animals at the site offer important additional insights into resources available to these hominins. The consilience of these different lines of evidence can help us to better understand Neandertal anterior tooth wear at Krapina, an important step in identifying variation among populations of this species in diet and other aspects of behavior.

\section{Background}

\subsection{Krapina anterior dental wear}

The Krapina Neandertal dental remains represent the largest and most complete hominin collection known to date [19]. The most extensive study of this collection is that of Wolpoff [7], whose comprehensive analyses in- cluded gross wear but not microwear. Wolpoff found a consistent and symmetrical wear pattern throughout the maxillae and mandibles, with the majority of the anterior teeth worn level and flat. However, mandible J did evince labial-lingual rounding of the anterior dentition, which he attributed to non-dietary anterior tooth use behaviors [7].

The relationship between the labial-lingual rounding observed by Wolpoff and dental microwear patterns was also explored in the Krapina sample [10]. Ryan recognized a pattern of microwear features that included gouges, proximal microflaking, and large pits on the occlusal surfaces of the anterior teeth. Fine wear striae were also observed running labial-lingually from the incisal edge toward the crown base. These patterns were most similar to his higharctic Alaskan Eskimo sample from Point Hope, and were attributed to clamping and pulling abrasive materials between the anterior teeth, and incising plant and/or meat resources [10].

The sample has been noted for the presence of idiopathic grooves on interproximal surfaces of several teeth [20], including a lower lateral incisor. In total, 14 teeth representing 10 individuals have such grooves located on the mesial or distal side of the tooth at the cement-enamel junction. This likely does not reflect the use of these teeth as tools, however, as microscopic striations and polish within the grooves bear what are thought to be the telltale signs of toothpick use [20]. This has been observed for a variety of modern humans and fossil hominins [21-23].

On the other hand, labial surface striations on the anterior teeth of the Krapina sample may well reflect use of these teeth as tools. Fox and Frayer [24] identified two scratch patterns on the labial surfaces of 82 front teeth at Krapina. The first pattern included features located close to the incisal edge, and was interpreted by the authors as indicative of grasping abrasive items between the upper and lower front teeth. This would imply that the Krapina Neandertals used their anterior dentition as a third hand, much like that recorded ethnographically in aboriginal arctic communities. The other scratch pattern was found on the central part of the labial surface, and was explained as the result of stone tools scraping across the surface during "stuff and cut" behaviors.

The striations on the labial surfaces these teeth are part of a larger category of evidence for diet and tooth use known as dental microwear. Studies of many different mammal species have shown, for example, that the pattern of microscopic scratching and pitting on the occlusal surface of a cheek tooth reflects the fracture properties of foods eaten in the days or weeks before the tooth was last used. Hard-object feeders, for example, typically have pit-laden surfaces, whereas tough food feeders more often have their teeth scored by long, parallel striations [25, 26]. Anterior 
dental microwear has also been examined as evidence for ingestive behaviors in numerous mammals. For example, primates that regularly use their incisors in food acquisition and processing typically have higher densities of microwear striations than those that do not $[27,28]$.

While counts and measurements of microscopic scratches and pits have shown important associations between microwear pattern and diet/tooth use, three-dimensional characterizations of overall surface textures have become an increasingly popular alternative to feature-based microwear studies [26, 29, 38]. Dental microwear texture analysis combines white-light confocal profilometry and scale-sensitive fractal analysis, an engineering protocol rooted in fractal geometry [31]. There are several distinct texture attributes that have proven useful in distinguishing groups based on diet and anterior tooth use behaviors (see below).

Dental microwear texture analyses of incisor teeth have been especially valuable for distinguishing bioarchaeological/ethnographic groups based on their food preferences, dietary and/or environmental abrasive loads, and non-dietary anterior tooth use practices [34, 39]. For example, groups that employ non-dietary anterior tooth use behaviors have lower anisotropy values than those that do not. This indicates more varied orientations of texture features rather than those more parallel, as would be expected of only incising food items. Further, high textural fill volume signaled high-magnitude loading among those groups that utilized non-dietary practices, and especially abrasive diets in those that did not. The latter groups also tended to have more heterogeneous wear surfaces $[34,39]$. Finally, groups that use their front teeth as tools and have abrasive diets tend to have highly complex microwear textures, those with variation in surface roughness dependent on the scale of observation [39], [see below].

To date, incisor microwear textures representing 13 bioarchaeological/ethnographic populations with known or inferred diets, abrasive loads, and/or degree/types of nondietary anterior tooth use have been collected. Results have made it evident that this approach can be quite valuable for testing hypotheses concerning the etiology of anterior tooth wear in Neandertals and other fossil taxa [39]. The data and analyses presented in this paper are consistent with previous results, and offer a unique perspective on the behavioral strategies of the Krapina Neandertals.

\section{Materials and methods}

The sample included in this study is comprised of one anterior tooth from each of 17 Krapina Dental People (KDP). Given the vagaries of fossil preservation and postmortem damage, it was necessary to include all anterior tooth types (not just $\mathrm{I}^{1} \mathrm{~s}$ ) in our analyses to maximize our sample size. We posit that combining anterior tooth types is reasonable because large-scale analyses of Neandertal and early modern human specimens have failed to find significant variation within individuals between maxillary and mandibular teeth, or between central and lateral incisors and canines [39].

The microwear texture data for the Krapina sample are compared to those for six bioarchaeological/ethnographic groups with different diets, non-dietary anterior tooth use behaviors, and environmental/dietary abrasive loads. The baseline data were originally published in Krueger and Ungar [34] and Krueger [39] [see also [40]]. Samples include I's of: Aleut $(n=24)$, Arikara $(n=18)$, Illinois Bluff ( $n=20)$, Puye Pueblo $(n=18)$, Nunavut Territory $(n=27)$, and Coast Tsimshian $(n=25)$. All specimens are housed at the US National Museum of Natural History in Washington D.C., except for the Nunavut Territory and Coast Tsimshian, which are curated at the Canadian Museum of Civilization in Gatineau, Québec.

\subsection{Krapina Sample}

The hominin collection from Krapina represents the largest Neandertal sample found to date, including 281 teeth or tooth fragments $[41,42]$. The majority of the remains were excavated from levels three and four, often referred to as the "Hominin Zone," and five to seven; however, the levels accumulated quickly, and all the hominin remains may be considered penecontemporaneous $[43,44]$. Electron spin resonance (ESR) dating places the Krapina Neandertals in marine oxygen isotope stage (MIS) 5e, and paleoenvironmental reconstructions have suggested a temperate forest climate in the region at that time $[17,18]$. The faunal assemblage includes Merck's rhinoceros, bison, auroch, giant deer, cave bear, brown bear, beaver, and horse $[16,18,45]$.

\subsection{Bioarchaeological comparative samples}

Aleut. The Aleut sample was collected by Ales Hrdlička in the late 1930s from Agattu, Amaknak, Kagamil, Unmak, and Unalaska Islands, all of which form part of the oceanic and rainy eastern archipelago of the Aleutian Islands [46]. These individuals have been dated to between 3400 to 400 BP [47]. The average Paleo-Aleut and Neo-Aleut $\delta^{14} \mathrm{C}$ and $\delta^{15} \mathrm{~N}$ values are -12.3 and 19.5 and -12.7 and 20.3, respectively [47], suggesting a marine diet of raw and dried fish, sea mammals, and shellfish, supplemented by foxes, rodents, birds, and tubers [34, 46-49]. 
Ethnographic and historic reports suggest the Aleut engaged in non-dietary anterior tooth use behaviors $[48,50]$ including softening wood for boat frames, grasping hides during clothing preparation, and even chewing leather straps for nourishment during lean months [34, 46-49].

Arikara. The Arikara (or Sahnish) sample was excavated by Matthew Stirling in the 1920s from the Mobridge site (39WW1), located in north-central South Dakota [53]. The sample dates from 400 to $300 \mathrm{BP}$, and the site, which is on the banks of the Missouri River, was temperate grassland during occupation $[54,55]$. The Arikara subsistence strategy was primarily focused on hunting bison and other large game, with the meat cut into strips and dried on large, open racks $[54,55]$. However, wild plants, such as black cherries, grapes, peppers, and pumpkin, and cultigens, including corn, squash, beans, sunflowers, were also consumed $[54,56]$.

There is no evidence in the archaeological, bioarchaeological, or ethnographic records of the Arikara using their anterior teeth in behaviors other than consuming foods; however, food processing techniques may have contributed to their considerable dental wear [57]. Sunflower seeds and maize were processed with stone mortars, which likely introduced abrasives into the meal $[54,57,58]$. Moreover, maize phytoliths may have heightened the abrasive load [57, 59].

Illinois Bluff. The Illinois Bluff sample was collected by Paul Titterington in the 1920s and 1930s, and was excavated from 33 Illinois Bluff Mounds overlooking the Illinois River in Jersey County, Illinois [15]. This sample dates to approximately 1400 to 1100 years BP, which places it in the Patrick phase of the Late Woodland tradition, with environmental conditions documented as humid and continental $[15,60]$.

The Illinois Bluff peoples were principally horticulturalists, but faunal and archeological evidence indicates they also relied on fish and hunted and gathered wild animals and plants $[60,61]$. Their cultigens included smartweed, maygrass, sunflower, marsh elder, maize, and squash, as well as wild plants, including wild fruits, berries, tubers, and nuts [60]. Mammals, such as white-tail deer, beavers, and gophers, were also consumed [60].

An analysis of the Illinois Bluff sample suggests that these people used their anterior dentition for non-dietary purposes. Specifically, Mayes [15] found a high frequency of gross anterior wear, with $14 \%$ having anterior tooth chipping, attributed to the use of the anterior dentition in occupational behaviors, such as stone tool production and retouching [15]. Heavy post-canine gross tooth wear also suggests this sample was exposed to a moderately heavy abrasive load, most likely from cultigen processing techniques [15].
Puye Pueblo. The Puye Pueblo sample was collected by Edgar Hewett in 1909 from the northern area of Pajarito Plateau (Tewa: Tsirege), west of the Rio Grande river in New Mexico, USA [62]. The site is arid to semiarid desert, and dates to between 1100 and 330 BP [62]. Historic accounts and archaeological data indicate that while the Puye Pueblo relied on a subsistence strategy of mostly squash, maize, and bean agriculture, they also descended to the canyon bottoms to hunt rabbit, deer, and fox [62]. Wild plants, such as grapes, yucca, prickly pear, plums, nuts, and beeweed were also eaten [62-64].

There are no ethnographic accounts of the Puye Pueblo engaging in non-dietary anterior tooth use behaviors; however, the degree of gross tooth wear typical in the sample suggests substantial dietary and environmental abrasives in or on their food. Stone-on-stone grinding technology, used to produce maize and other types of meal, as well as phytoliths in cereals likely explains their heavy tooth wear. Moreover, living in a more open mesa setting would have made Puye Pueblo foods susceptible to windblown grit and dust.

Nunavut Territory. The Nunavut Territory skeletal remains are from the polar arctic sites of Native Point, Kamarvik, and Silumiut, located in the northwest Hudson Bay area. The Native Point site, excavated by Henry Collins in the 1950s, is attributed to the Sadlermiut, an Inuit population of both Thule and Dorset genetic ancestry [65]. These burials have been dated to 650 to 100 years BP, and the average $\delta^{14} \mathrm{C}$ and $\delta^{15} \mathrm{~N}$ values for this sample were -13.2 and 20.3 , respectively, consistent with a diet dominated by meat - e.g., caribou, walrus, ringed seal, and seabirds $[65,66]$. Faunal analyses support an emphasis on caribou, with nearly $25 \%$ of the assemblage identified as such $[67,68]$. The Thule burials from Kamarvik and Silumiut were excavated by Charles Merbs in the late 1960s. These burials have been radiocarbon dated to 950 to 350 years BP, and their average $\delta^{14} \mathrm{C}$ and $\delta^{15} \mathrm{~N}$ values were -14.3 and 17.5 , indicating a heavy reliance on terrestrial mammals, such as caribou, as well as lower-level marine taxa [65].

The Nunavut Territory dental remains show extensive evidence of trauma [69-71]. Chipping, flaking, fracturing of the tooth crowns, labial wear, and antemortem tooth loss have been attributed to women using the anterior dentition as tools for tasks such as preparing skins for clothing, tents, and boats [71]. Frequency of antemortem tooth loss and wear was also high for men; this has been recognized as evidence for use of the anterior dentition in activities such as bow drilling [71].

Postcanine tooth gross wear is also extensive, and most likely indicates heavy abrasive loads [71]. Ethnographic accounts of Inuit in the area detail the practice of drying 
meat on the ground, as well as storing it in houses covered by sand, moss, and peat [72]. Moreover, sand was often used to clean houses [73]. These practices would no doubt have contributed considerable dietary and environmental abrasives to the Nunavut Territory Inuit lifestyle.

Coast Tsimshian. Boardwalk and Reservoir are two of eleven sites found among the Digby and Kaien Islands in the oceanic climate, temperate rainforest areas of Prince Rupert Harbour. The area was excavated by George MacDonald during the late 1960s and early 1970s as part of the North Coast Prehistory Project [74]. The hundreds of individuals excavated were determined to be of Coast Tsimshian ancestry, and have been dated to between 4000 and $700 \mathrm{BP}[12,74]$.

Faunal analyses of the sites indicate that the Coast Tsimshian Inuit diet was dominated by fish, especially salmon, though Pacific herring, Pacific tomcod, sculpin, sole, flounder, and other fish were all present at the site in fewer frequencies [74]. Land and sea mammals, such as mule deer, blacktail deer, sea otters, beaver, and seals, as well as birds, were also consumed on rare occasion [74].

Non-dietary anterior tooth use behaviors have also been suggested for the Coast Tsimshian [12]. Gross wear patterns of the anterior teeth have been attributed to weaving practices; root fibers for blanket and basketry production were moistened with saliva and softened using the anterior dentition, which, over time, produced linear grooves on the incisal edges [12]. This behavior is documented in ethnographic records of blanket and basket weaving in Tsimshian culture, and in accounts of the nearby Tlingit, a group that shared elements of material culture practices with the Tsimshian [12].

\subsection{Data collection}

This study used high-resolution replicas of the Krapina Neandertals and modern human anterior teeth. First, the labial surface of each tooth was carefully cleaned with cotton swabs and acetone. A high-resolution, regular body polysiloxane dental impression material, President's Jet (Coltène-Whaledent), was used to create a mold of each tooth. High-resolution epoxy casts were produced using Epotek 301 base and hardener (Epoxy Technologies). This protocol has been shown to reproduce microwear features to a fraction of a micron [75].

As described in Krueger and Ungar [34], the labial surface nearest the incisal edge of each tooth was inspected for dental microwear using a light microscope at low magnification. Those observed to preserve antemortem wear were scanned using a Sensofar Pl $\mu$ white-light confocal profiler (Solarius Development Inc., Sunnyvale, California), which has a lateral sampling interval of $0.18 \mu \mathrm{m}$ and a vertical resolution of $0.005 \mu \mathrm{m}$ [31]. Four adjacent scans of each tooth surface were taken with a $100 x$ objective lens, for a total work envelope of $276 \times 204 \mu \mathrm{m}$ [31]. The point clouds for each individual were leveled and any defects, such as dust or preservative, were deleted using Solarmap Universal software (Solarius Development Inc., Sunnyvale, California). Resultant data were then imported into Toothfrax and SFrax scale-sensitive fractal analysis (SSFA) software packages (Surfract, www.surfract.com) for surface texture characterization.

Five texture variables, complexity $(A s f)$, anisotropy (epLsar), textural fill volume $(T f v)$, and two variants of heterogeneity (HAsf $c_{9}$ and $H A s c_{81}$ - see below for descriptions) were then used to characterize individual microwear surfaces. These are all described in detail in Scott et al. [31]. Complexity is a measure of change in roughness with scale of observation - heavily pitted surfaces with features of varying sizes typically have high complexity values. Anisotropy is a measure of surface texture directionality - a surface dominated by fine parallel striations is highly anisotropic. Textural fill volume is a measure of the average diameter and depth of features removed from a microwear surface. Since this measures the difference between volumes of large $(10 \mu \mathrm{m})$ and small $(2 \mu \mathrm{m})$ square cuboids that "fill" a surface, high values indicate a dominance of features of intermediate size. Finally, heterogeneity is a measure of variation in complexity across a sampled surface. In this case, sampled areas were divided into $3 \times 3$ grids $\left(H A s f c_{9}\right)$ and $9 \times 9$ grids $\left(H A s f c_{81}\right)$.

\subsection{Statistical analyses}

Median values for each attribute were calculated for each of the four scans representing each individual [31]. A multivariate analysis of variance (MANOVA) was performed on rank-transformed data [76] with the fossil and baseline samples as independent variables and the texture attributes as dependent variables. Analyses of variance (ANOVAs) for individual texture attributes and pairwise comparisons for the samples were conducted as needed to determine the sources of significant variation. Both Tukey's HSD and Fisher's LSD tests were used to balance risks of Type I and Type II errors [77]. It is important to note that Tukey's HSD test results were used as the benchmark for significance, while Fisher's LSD test results were considered suggestive or of marginal significance.

\section{Results}

The Krapina sample had a fairly unremarkable anterior dental microwear pattern compared with the baseline 
Table 1. Descriptive statistics.

\begin{tabular}{ccccccc}
\hline Group & & Asfc & epLsar & Tfv & HAsfc & HAsfc 81 \\
\hline \hline Krapina & Mean & 1.27 & $\mathbf{0 . 0 0 3 1}$ & 5810.11 & $\mathbf{0 . 4 2}$ & $\mathbf{0 . 6 8}$ \\
$\boldsymbol{n}=17$ & Median & 1.26 & $\mathbf{0 . 0 0 3 1}$ & $\mathbf{4 9 0 6 . 2 2}$ & $\mathbf{0 . 4 0}$ & $\mathbf{0 . 6 6}$ \\
& S.D. & $\mathbf{0 . 4 5}$ & $\mathbf{0 . 0 0 1 3}$ & 3620.88 & $\mathbf{0 . 0 8}$ & $\mathbf{0 . 1 6}$ \\
\hline Aleut & Mean & 0.93 & 0.0030 & 7434.50 & 0.38 & 0.61 \\
$n=24$ & Median & 0.90 & 0.0030 & 7334.67 & 0.38 & 0.55 \\
& S.D. & 0.45 & 0.0011 & 5272.19 & 0.07 & 0.12 \\
\hline Arikara & Mean & 0.77 & 0.0036 & 1897.76 & 0.37 & 0.56 \\
$n=18$ & Median & 0.65 & 0.0032 & 634.31 & 0.36 & 0.55 \\
& S.D. & 0.40 & 0.0016 & 2466.36 & 0.08 & 0.12 \\
\hline IL Bluff & Mean & 0.97 & 0.0027 & 1950.52 & 0.40 & 0.57 \\
$n=20$ & Median & 0.87 & 0.0025 & 594.39 & 0.36 & 0.55 \\
& S.D. & 0.37 & 0.0013 & 2989.45 & 0.08 & 0.09 \\
\hline Puye & Mean & 1.24 & 0.0040 & 5093.03 & 0.48 & 0.75 \\
$n=18$ & Median & 0.87 & 0.0039 & 4284.68 & 0.45 & 0.63 \\
& S.D. & 1.01 & 0.0013 & 4183.08 & 0.14 & 0.32 \\
\hline Nunavut & Mean & 3.28 & 0.0020 & 12449.27 & 0.60 & 1.09 \\
$n=27$ & Median & 2.60 & 0.0018 & 12905.65 & 0.47 & 1.05 \\
& S.D. & 2.13 & 0.0010 & 3464.04 & 0.32 & 0.38 \\
\hline Tsimshian & Mean & 1.86 & 0.0024 & 5766.64 & 0.46 & 0.70 \\
$n=25$ & Median & 1.81 & 0.0019 & 3079.71 & 0.46 & 0.68 \\
& S.D. & 0.78 & 0.0013 & 5196.40 & 0.12 & 0.20 \\
\hline
\end{tabular}

Table 2. MANOVA and ANOVA results of ranked microwear texture data.

\begin{tabular}{ccccc}
\hline MANOVA & Test Statistic & $F$ & $d f$ & $p$ \\
\hline \hline Wilks' Lambda & 0.279 & 6.940 & 30,554 & 0.000 \\
Pillai Trace & 0.971 & 5.704 & 30,710 & 0.000 \\
Hotelling's Trace & 1.780 & 8.093 & 30,682 & 0.000 \\
\hline ANOVAs & $F$ & $d f$ & $p$ \\
\hline \hline Asfc & 18.707 & 6 & 0.000 \\
epLsar & 6.719 & 6 & 0.000 \\
Tfv & 17.507 & 6 & 0.000 \\
HAsfc & 5.345 & 6 & 0.000 \\
HAsfc $_{81}$ & 11.875 & 6 & 0.000 \\
\hline
\end{tabular}

groups. These Neandertals had moderate microwear texture values that fell within the ranges of at least some of the baseline groups for all attributes. Nevertheless, MANOVA test results indicated significant variation in anterior dental microwear textures among the samples, and individual ANOVAs revealed variation among the groups in all microwear texture attributes. Results are illustrated in Figures 1 and 2, and descriptive and analytical statistics are presented in Tables 1 and 2 .

Complexity. The Krapina Neandertals had a moderate texture complexity average. Tukey's HSD pairwise comparisons indicated that the Krapina Neandertals had sig-
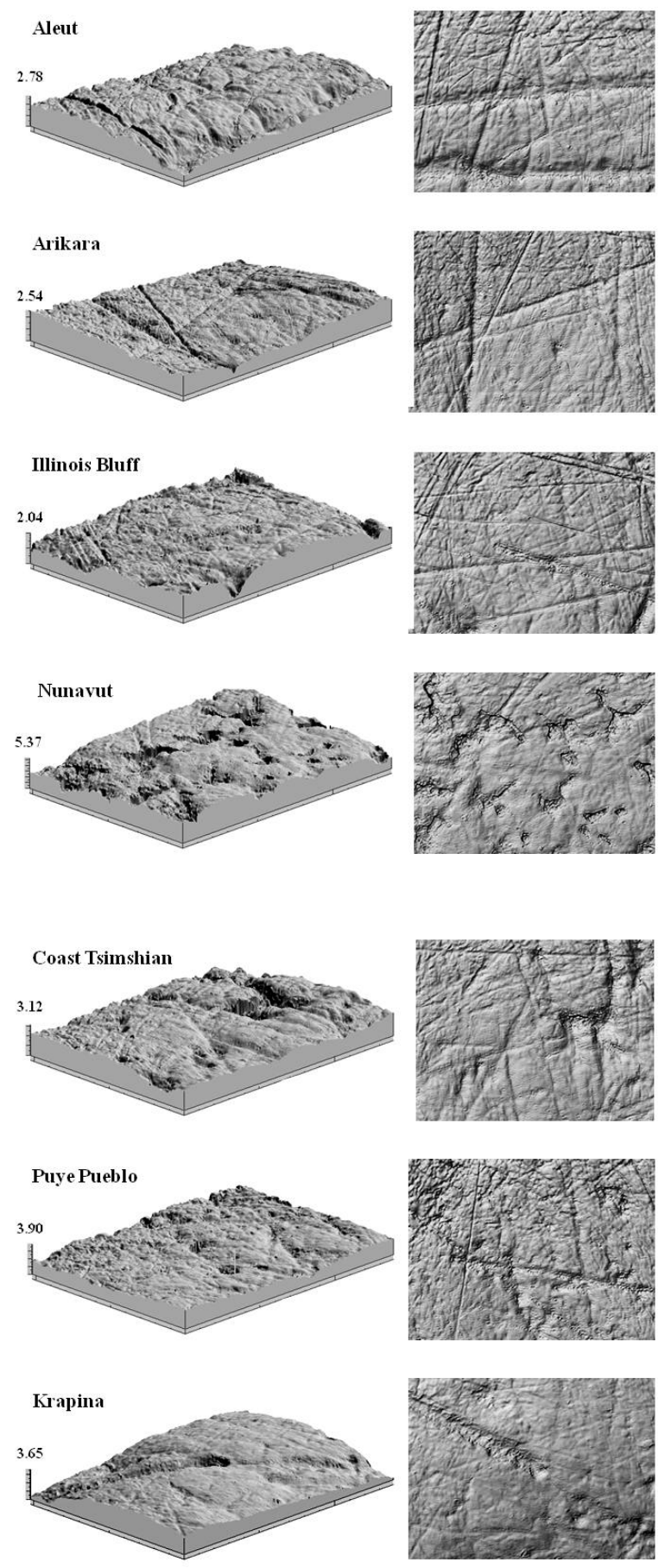

Figure 1. Two- and three-dimensional photo simulations of the Krapina Neandertals and six comparative bioarchaeological samples. These images represent one of four adjacent scans for each individual, and measure an area of $102 \times 138 \mu \mathrm{m}$. 
Table 3. Multiple comparisons tests.

\begin{tabular}{|c|c|c|c|c|c|c|}
\hline \multicolumn{7}{|l|}{ 1. Asfc } \\
\hline & Aleut & Arikara & IL Bluff & Puye & Nunavut & Tsimshian \\
\hline Krapina & $24.571^{*}$ & $37.252^{* * *}$ & $21.554^{*}$ & 15.696 & $-44.359^{* * *}$ & $-24.911^{*}$ \\
\hline \multicolumn{7}{|l|}{ 2. epLsar } \\
\hline & Aleut & Arikara & IL Bluff & Puye & Nunavut & Tsimshian \\
\hline Krapina & 2.293 & -14.103 & 11.872 & $-27.186^{*}$ & $35.129^{*}$ & $25.667^{*}$ \\
\hline \multicolumn{7}{|l|}{ 3. $T f v$} \\
\hline & Aleut & Arikara & IL Bluff & Puye & Nunavut & Tsimshian \\
\hline Krapina & -7.400 & $38.020^{* * *}$ & $41.603^{* * *}$ & 6.964 & $-45.0174^{* * *}$ & 4.073 \\
\hline \multicolumn{7}{|l|}{ 4. HAsfca } \\
\hline & Aleut & Arikara & IL Bluff & Puye & Nunavut & Tsimshian \\
\hline Krapina & 14.373 & 24.206 & 13.681 & -20.739 & $-28.500^{*}$ & -10.134 \\
\hline \multicolumn{7}{|l|}{ 5. $H A s f_{81}$} \\
\hline & Aleut & Arikara & IL Bluff & Puye & Nunavut & Tsimshian \\
\hline Krapina & 18.708 & $31.139^{*}$ & $28.950 *$ & -2.222 & $-43.148^{* * *}$ & -0.440 \\
\hline
\end{tabular}
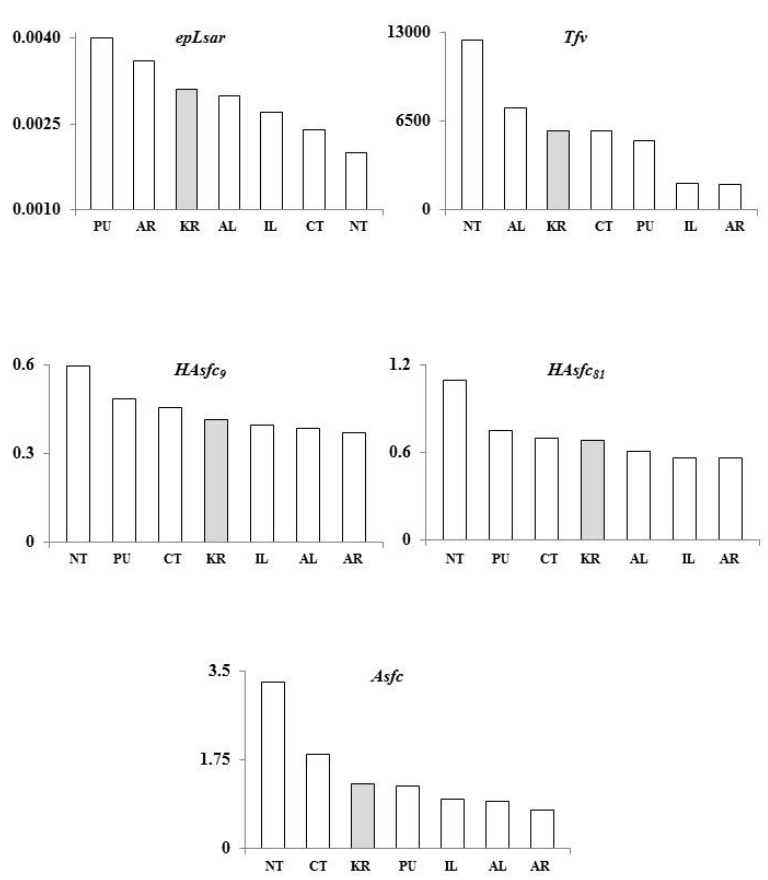

Figure 2. Bar charts showing the mean texture values of the Krapina Neandertals and six comparative bioarchaeological samples. $\mathrm{KR}=$ Krapina, $\mathrm{AL}=$ Aleut, $\mathrm{AR}=$ Arikara, $\mathrm{CT}=$ Coast Tsimshian, IL = Illinois Bluff, NT = Nunavut Territory, and $\mathrm{PU}=$ Puye Pueblo. nificantly higher average Asfc values than did the Arikara but lower values than the Nunavut Territory. Further, Fisher's LSD tests suggested that the Krapina sample had higher average complexity than that of the Aleut and Illinois Bluff but a lower average than the Coast Tsimshian. The Krapina sample did not differ according to either test from the Puye Puebloans in Asfc.

Anisotropy. The Krapina sample also had a moderate average epLsar value. In fact, the Krapina Neandertal anisotropy values did not differ significantly from any of the baseline samples according to Tukey's HSD test results. On the other hand, Fisher's test results suggested that the Krapina sample had marginally lower anisotropy values than the Puye Pueblo sample, but higher anisotropy than the Nunavut Territory and Prince Rupert Harbour samples.

Textural fill volume. The Krapina sample also had Tfv values within the ranges of the baseline groups. While the Neandertal Tf $f_{V}$ did not differ from those of the Aleut, Puye Pueblo, or Coast Tsimshian groups according to either test, Tukey's HSD test results indicated that the Krapina sample had significantly higher texture fill volumes than the Arikara and Illinois Bluff, and significantly lower values than the Nunavut Territory sample.

Heterogeneity. Finally, the Krapina Neandertals also had intermediate values for heterogeneity of complexity across sampled areas. In most cases, they did not differ from the baseline samples (especially for HAsf $c_{9}$ ). On the other hand, the Krapina Neandertal heterogeneity average was lower than that of the Nunavut sample (according to Tukey's HSD test for HAsf $c_{81}$ and Fisher's LSD test for $H A s f c_{9}$ ), and marginally higher (Fisher's LSD test result 
$p<.05$ for $\left.H A s f c_{81}\right)$ than those of the Arikara and Illinois Bluff samples.

\section{Discussion}

These data show that the anterior dental microwear signatures of the Krapina Neandertals are not extreme, but they do vary in some ways from each of the baseline samples of known or inferred diet, non-dietary anterior tooth use behaviors, and abrasive loads. Although Neandertals are most often compared to arctic populations in functional morphological analyses, data presented here suggest that high latitude human foragers may not always make the best analogs. We can better understand anterior tooth use in the Krapina Neandertals by comparing their microwear texture values with a variety of baseline groups that vary in their observed or inferred diets and other behaviors, as well as in their abrasive environments. Each texture attribute will be considered separately.

Complexity $(A s f c)$. Previous analyses of anterior tooth microwear texture complexity have suggested that Asfc represents a balance between level of abrasives exposure and level of non-dietary anterior tooth use activities [39]. If both abrasive exposure and non-dietary tasks (i.e., use of teeth as tools or as a third hand) are high, a high complexity value will result; the effects appear to be cumulative. If only one effect is high, or if both are moderate, this will result in moderate complexity values. Our interpretations are predicated on this understanding.

The Krapina sample had a mean Asfc value of 1.27, which was most similar to that of the Puye Pueblo (1.24). The Puye Pueblo are described as being exposed to heavy environmental and dietary abrasive loads; however, they are not reported to have used their anterior teeth as tools. The moderate complexity values reflect this. On the other hand, the Krapina Neandertal sample had significantly lower Asfc values than did the Nunavut Territory group and marginally lower Asfc values than did the Coast Tsimshian sample. The Nunavut Territory peoples used their anterior teeth extensively as tools, in this case as clamps for grasping, and were exposed to heavy abrasive loads. This is consistent with their high complexity average. The Coast Tsimshian people employed non-dietary activities in the form of softening plant fibers for weaving practices, and were likely exposed to heavy levels of abrasives, consistent with slightly higher complexity values. It appears as if the Krapina individuals occasionally used their anterior dentition for non-dietary tasks, and were exposed to a moderate abrasive load.

Anisotropy (epLsar). Previous analyses of anterior dental microwear textures suggest that anisotropy can help dis- tinguish dietary from non-dietary anterior tooth use [34, 39]. High anisotropy values on the labial surfaces of the anterior teeth evidently reflect abrasives being dragged apicocervically, as would be expected during the incising of food items. However, low anisotropy values, or a lack of feature directionality across the labial surface, suggest that the anterior teeth were used in a variety of tasks, including non-dietary anterior tooth use (e.g. clamping, grasping, tool production, etc.).

All the baseline groups with low mean anisotropy values have been reported or inferred to have employed nondietary uses of the anterior teeth $[34,39]$. Of those considered in this study, the Arikara and Puye Pueblo are not inferred to have utilized non-dietary anterior tooth use, and this is consistent with their high anisotropy values. On the other hand, the Illinois Bluff, Aleut, Nunavut Territory, and Coast Tsimshian all used their front teeth in various non-dietary activities, and their range of low anisotropy values is consistent with these different behaviors.

The Krapina Neandertal mean anisotropy value is within but near the upper end of the range for groups observed or inferred to have engaged in non-dietary anterior tooth use activities. Their epLsar value is similar to that of the Aleut, a group known to have used their anterior dentition for hide preparation, softening wood fibers, and other tasks, at least on occasion. The fact that the Coast Tsimshian and high-arctic Nunavut individuals had lower average values for epLsar than the Krapina sample suggests that these Neandertals may have engaged in less frequent or more moderate levels of non-dietary anterior tooth use.

Textural fill volume (Tfv). This attribute has been associated with either loading regime or with abrasive particle density or size, depending on whether the group participated in non-dietary anterior tooth use behaviors [34, 39]. High Tfv values are typically found in those groups that are reported or inferred to engage in high stress or heavy loading during non-dietary anterior tooth use practices. Alternatively, those that are inferred to have used their front teeth only in food acquisition and processing show higher $T f v$ values when exposed to heavy densities of abrasive particles.

The Krapina Neandertal Tfv values were moderate, which, in combination with its epLsar and Asfc values, suggest some non-dietary anterior tooth use. The Krapina average value is similar to that of the Coast Tsimshian peoples, which are reported to have used their anterior teeth in softening plant fibers for blanket and basketry weaving. While we do not suggest that the Krapina Neandertals were producing blankets and baskets, these results are consistent with a lower magnitude or frequency of ante- 
rior loading compared with the Nunavut Territory sample. It is interesting to note that the Krapina $T f v$ data are closest to the sample that lived in a temperate forest environment and utilized plant materials in non-dietary behaviors, especially given mounting evidence regarding the consumption of plants by Neandertals [78].

Heterogeneity (HAsfc). Heterogeneity of complexity across anterior tooth microwear surfaces has been associated in past studies with abrasive exposure. Groups living in areas with heavy abrasive loads tend to have more heterogeneous microwear textures [34, 39]. However, non-dietary anterior tooth use behaviors may intensify the signal [39]. When we combine heterogeneity results with those from the other groups, the position of the Krapina HAsfc mean is between that of the Nunavut Territory sample on the one hand, and those of the Arikara and Illinois Bluff groups on the other. Again, this is most consistent with moderate non-dietary tooth use combined with a moderate abrasive exposure.

\section{Conclusion}

The results of this study are consistent with the use of anterior teeth by Krapina Neandertals in non-dietary tooth use behaviors, but they also suggest that analogies should not be limited to high-Arctic populations. While the Krapina Neandertals were similar to the Aleut in anisotropy, suggesting similar non-dietary anterior tooth use behaviors, they were closer to the Coast Tsimshian in textural fill volume and heterogeneity. This is consistent with moderate use of the front teeth in non-dietary activities, perhaps including some plant processing. The Krapina individuals were similar to the Puye Pueblo people in their complexity, which may have resulted not solely from heavy abrasive exposure, as is likely for the Puye Pueblo sample, but from moderate abrasive loads coupled with moderate non-dietary anterior tooth use behaviors.

In sum, the Krapina Neandertals were more multifaceted in their anterior tooth wear patterns than a simple Arctic analogy might suggest. It is clear that, generally speaking, the Krapina Neandertals were not participating in intense clamping and grasping activities associated with Arctic populations, but may have been drawing other types of materials between their anterior teeth. While this study addresses the overall anterior tooth wear signatures of the Krapina Neandertals, there is still some question as to what caused the unique and excessive labial-lingual rounding present on some noteworthy Neandertal specimens, including mandible J from Krapina. This, we posit, was not likely due to moderate or occasional non-dietary anterior tooth use, as seen in the overall Krapina sam- ple, but perhaps reflects an individual, more intense nondietary anterior tooth use regimen.

\section{Acknowledgements}

We thank the anonymous reviewers who offered helpful insights to this manuscript. We are grateful to David Frayer, Ivana Fiore, and Luca Bondioli for access to the Krapina Neandertal anterior dental cast collection. We also thank curators at the US National Museum of Natural History and Canadian Museum of Civilization, as well as the Inuit Heritage Trust for their permission to study specimens in their care. This study was funded by the US National Science Foundation DDIG program (BCS-0925818) and the LSB Leakey Foundation.

\section{References}

[1] Stewart T.D., The restored Shanidar I skull. In: The Annual Report of the Smithsonian Institution for 1958. Washington DC, 1959, 473-480.

[2] Puech P.-F., The diet of early man: evidence from abrasion of teeth and tools. Current Anthropology, 1979, 20, 590-591

[3] Puech P.-F., Tooth wear in La Ferrassie man. Current Anthropology, 1981, 22, 424-429

[4] Wallace J.A., Did La Ferrassie I use his teeth as a tool? Current Anthropology, 1975, 16, 393-401

[5] Smith F.H., On anterior tooth wear at Krapina and Ochoz. Current Anthropology, 1976, 17, 167-168

[6] Smith P., Dental pathology in fossil hominids: what did Neanderthals do with their teeth? Current Anthropology, 1976, 17, 149-151

[7] Wolpoff M.H., The Krapina dental remains. American Journal of Physical Anthropology, 1979, 50, 67-114

[8] Brace C.L., Environment tooth form and size in the Pleistocene. Journal of Dental Research, 1967, 46, 809-816

[9] Brace C.L., Comment on: Did La Ferrassie I use his teeth as a tool? Current Anthropology, 1975, 16, 396397

[10] Ryan A.S., Anterior dental microwear in hominid evolution: comparisons with human and nonhuman primates. PhD thesis, University of Michigan, United States, 1980

[11] Brace C.L., Ryan A.S., Smith B.H., Comment: tooth wear in La Ferrassie man. Current Anthropology, 1981, 22, 426-430

[12] Cybulski J.S., Tooth wear and material culture: precontact patterns in the Tsimshian area British 
Columbia. Syesis, 1974, 7, 31-35

[13] Lukacs J.R., Pastor R.F., Activity-induced patterns of dental abrasion in prehistoric Pakistan: evidence from Mehrgarh and Harappa. American Journal of Physical Anthropology, 1988, 76, 377-398

[14] Foote B.A., The Tigara Eskimos and their environment. North Slope Borough Commission on Iñupiat History Language and Culture, Point Hope, 1992

[15] Mayes A.T., Patterns through time: interactions between changes in subsistence and human dentition at Illinois Bluff, Jersey County, Illinois and Spiro Mounds, Oklahoma. PhD thesis, University of Colorado, United States, 2001

[16] Malez M., A new look at the stratigraphy of the Krapina prehistoric site. In: Malez M. (Ed.), Krapina 1899-1969. Jugoslavenske Akademije Znanosti i Umjetnosti, Zagreb, 1970, 13-44

[17] Rink W.J., Schwarcz H.P., Smith F.H., Radovĉić J., ESR ages for Krapina hominids. Nature, 1995, 378, 24

[18] Patou-Mathis M., Analyses taphonomique et palethnographique du matériel osseux de Krapina (Croatie): Nouvelles données sur la faune et les restes humains [Taphonomical and Palethnographical Analysis of the bone material from Krapina (Croatia): new data on the faunal and human remains]. Préhistoire Européenne, 1997, 10, 63-90

[19] Frayer D.W., The Krapina Neandertals: a comprehensive centennial illustrated bibliography. Croatian Natural History Museum, Zagreb, 2006

[20] Frayer D.W., Russell M.D., Artificial grooves on the Krapina Neanderthal teeth. American Journal of Physical Anthropology, 1987, 74, 393-405

[21] Schour I., Sarnat B.G., Oral manifestations of occupations origin. Journal of the American Medical Association, 1942, 120, 1197-1201

[22] Kaidonis J.A., Richards L.C., Townsend G.C., Abrasion: an evolutionary and clinical view. Australian Prosthodontics Journal, 1992, 6, 9-16

[23] Ungar P.S., Grine F.E., Teaford M.F., Pérez-Pérez A., 2001. A review of interproximal wear grooves on fossil hominin teeth with new evidence from Olduvai Gorge. Archives of Oral Biology, 2001, 46, 285-292

[24] Fox C.L., Frayer D.W., Non-dietary marks in the anterior dentition of the Krapina Neanderthals. International Journal of Osteoarchaeology, 1997, 7, 133-149

[25] Ungar P.S., Reconstructing the diets of fossil primates. In: Plavcan J.M., Kay R.F., Jungers W.L., van Schaik C.P. (Eds.), Reconstructing Behavior in the Primate Fossil Record. Kluwer Academic/Plenum Publishers, New York, 2002, 261-296

[26] Ungar P.S., Scott R.S., Scott J.R., Teaford M. Dental microwear analysis: historical perspectives and new approaches. In: Irish J.D., Nelson G.C. (Eds.), Technique and Application in Dental Anthropology. Cambridge University Press, Cambridge, 2008, 389-425

[27] Kelley J., Incisor microwear and diet in three species of Colobus. Folia Primatologia, 1990, 55, 73-84

[28] Ungar P.S., Patterns of ingestive behavior and anterior tooth use differences in sympatric anthropoid primates. American Journal of Physical Anthropology, 1994, 95, 197-219

[29] Ungar P.S., Brown C.A., Bergstrom T.S., Walker A., Quantification of dental microwear by tandem scanning confocal microscopy and scale-sensitive fractal analyses. Scanning, 2003, 25, 185-193

[30] Scott R.S., Ungar P.S., Bergstrom T.S., Brown C.A., Grine F.E., Teaford M.F., Walker A., Dental microwear texture analysis reflects diets of living primates and fossil hominins. Nature, 2005, 436, 693-695.

[31] Scott R.S., Ungar P.S., Bergstrom T.S., Brown C.A., Childs B.E., Teaford M.F., Walker A., Dental microwear texture analysis: technical considerations. Journal of Human Evolution, 2006, 51, 339-349

[32] Ungar P.S., Merceron G., Scott R.S., Dental microwear texture analysis of varswater bovids and early Pliocene paleoenvironments of Langebaanweg Western Cape Province South Africa. Journal of Mammalian Evolution, 2007, 14, 163-181

[33] Krueger K.L., Scott J.R., Kay R.F., Ungar P.S., Technical note: dental microwear textures of "Phase I" and "Phase II" facets. American Journal of Physical Anthropology, 2008, 137, 485-490

[34] Krueger K.L., Ungar P.S., Incisor microwear textures of five bioarchaeological groups. International Journal of Osteoarchaeology, 2010, 20, 549-560

[35] Ungar P.S., Grine F.E., Teaford M.F., Dental microwear and diet of the Plio-Pleistocene hominin Paranthropus boisei. PLoS ONE, 2008, 3, 1-6

[36] Scott J.R., Ungar P.S., Jungers W.L., Godfrey L.R., Scott R.S., Simons E.L., Teaford M.F., Walker A., Dental microwear texture analysis of the archaeolemurids and megaladapids two families of subfossil lemurs from Madagascar. Journal of Human Evolution, 2009, 56, 405-416

[37] Merceron G.M., Scott J.R., Scott R.S., Geraads D., Spassov N., Ungar P.S., Seed predation for an early Colobine as a link between frugivory and folivory? Evidence from dental microwear texture analysis of Mesopithecus (Late Miocene of Eurasia). Journal of Human Evolution, 2009, 57, 732-738

[38] Daegling D.J., McGraw W.S., Ungar P.S., Pampush J.D., Vick A.E., Bitty E.A., Hard-object feeding in Sooty Mangabeys (Cercocebus 
atys) and interpretation of early hominin feeding ecology. PLoS ONE, 2011, 6(8), e23095. doi:10.1371/journal.pone.0023095

[39] Krueger K.L., Dietary and behavioral strategies of Neandertals and anatomically modern humans: evidence from anterior dental microwear texture analysis. PhD thesis, University of Arkansas, United States, 2011

[40] Ungar P.S., Spencer M.A., Incisor microwear diet and tooth use in three Amerindian populations. American Journal of Physical Anthropology, 1999, 109, 387396

[41] Simek J.F., Smith F.H., Chronological changes in stone tool assemblages from Krapina (Croatia). Journal of Human Evolution, 1997, 32, 561-575

[42] Karavanić I., The Middle Paleolithic settlement of Croatia. In: Conard N.J. (Ed.), Settlement Dynamics of the Middle Paleolithic and Middle Stone Age, volume II. Kerns Verlag, Tübingen, 2004, 251-267

[43] Gorjanovič-Kramberger, D., Život i kultura diluvijalnoga covjeka iz Krapine u Hrvatskoj. Volume 23, Duro Trpinac, Zagreb, 1913

[44] Smith F.H., The Neandertal remains from Krapina: a descriptive and comparative study. University of Tennessee Reports of Investigations 15. University of Tennessee Press, Knoxville, 1976

[45] Osborn H.F., The Krapina Neanderthaloids. In: Osborn H.F. (Ed.), Men of the Old Stone Age: their Environment, Life and Art. New York: Charles Scribner's Sons, New York, 1915, 181-185

[46] Hrdlička A., The Aleutian and Commander Islands and their inhabitants. Wistar Institute of Anatomy and Biology, Philadelphia, 1945

[47] Coltrain J.B., Temporal and dietary reconstruction of past Aleut populations: stable- and radio-isotope evidence revisited. Arctic, 2010, 63, 391-398

[48] Moorrees C.F.A., The Aleut dentition: a correlative study of dental characteristics in an Eskimoid people. Harvard University Press, Cambridge, 1957

[49] Hoffman K.L., Unalaska Aleut subsistence adaptations at the time of early Russian contact as represented in the Reese Bay artifact assemblage. MA thesis, University of Arkansas, United States, 1993

[50] Merbs C., Anterior tooth loss in Arctic populations. Southwestern Journal of Anthropology, 1968, 24, 20 32

[51] Campbell A., A voyage round the world from 1806 to 1812. University of Hawaii Press, Honolulu, 1967

[52] Oliver E.R., Journal of an Aleutian year. University of Washington Press, Seattle, 1988

[53] Jantz R.L., Microevolutionary change in Arikara crania: a multivariate analysis. American Journal of
Physical Anthropology, 1973, 38, 15-26

[54] Meyer R.W., The village Indians of the upper Missouri. University of Nebraska Press, Lincoln, 1977

[55] Tuross N., Fogel M.L., Stable isotope analysis and subsistence patterns at the Sully site. In: Owsley D.W., Jantz R.L. (Eds.), Skeletal Biology in the Great Plains: Migration, Warfare, Health and Subsistence. Smithsonian Institution Press, Washington DC, 1994, 283-289

[56] Hurt W.R., Seasonal economic and settlement patterns of the Arikara. Plains Anthropology, 1969, 14, 32-37

[57] Leigh R.W., Dental pathology of Indian tribes of varied environmental and food conditions. American Journal of Physical Anthropology, 1925, 8, 179-199

[58] Teaford M.F., Lytle J.D., Brief communication: dietinduced changes in rates of human tooth microwear: a case study involving stone-ground maize. American Journal of Physical Anthropology, 1996, 100, 143147

[59] Piperno D.R., Phytolith analysis: an archaeological and geological perspective. Academic Press, San Diego, 1988

[60] Kelly L.S., Cross P.G., Zooarchaeology. In: Bareis C.J., Porter J.W. (Eds.), American Bottom Archaeology. University of Illinois Press, Chicago, 1984, 225-226

[61] Spencer R.F., Jennings J.D., The Native Americans: prehistory and ethnology of the North American Indians. Harper and Row, New York, 1965

[62] Barnes E., Puye and the Pajarito: historical background. In: Barnes E. (Ed.), Developmental Defects of the Axial Skeleton in Paleopathology. University of Colorado Press, Boulder, 1994, 298-317

[63] Hewett E.L., Pajarito Plateau and its ancient people. University of New Mexico Press, Albuquerque, 1938

[64] Trierweiler W.N., Prehistoric Tewa economy: modeling subsistence production on the Pajarito Plateau. Garland Publishing, New York, 1990

[65] Coltrain J.B., Sealing whaling and caribou revisited: additional insights from the skeletal isotope chemistry of eastern Arctic foragers. Journal of Archaeological Science, 2009, 36, 764-775

[66] Coltrain J.B., Hayes M.G., O'Rourke D.H., Sealing whaling and caribou: the skeletal isotope chemistry of Eastern Arctic foragers. Journal of Archaeological Science, 2004, 31, 39-57

[67] Collins H.B., Bering Strait to Greenland. In: Campbell J.M. (Ed.), Prehistoric Cultural Relations Between the Arctic and Temperate Zones of North America. Arctic Institute of North American Technical Paper 11. Arctic Institute of North America, Montreal, 1962, 126-139 
[68] Ryan K., Comments on Coltrain et al., Journal of Archaeological Science 31, 2004 "Sealing, whaling and caribou: the skeletal isotope chemistry of eastern Arctic foragers", and Coltrain, Journal of Archaeological Science 36, 2009 "Sealing, whaling and caribou revisited: additional insights from the skeletal isotope chemistry of eastern Arctic foragers". Journal of Archaeological Science, 2011, 38, 2858-2865

[69] Turner C., Cadien J., Dental chipping in Aleuts, Eskimo, and Indians. American Journal of Physical Anthropology, 1969, 31, 303-310

[70] Merbs C., Patterns of activity-induced pathology in a Canadian Inuit population. National Museum of Man Mercury Series Archaeological Survey of Canada Paper No. 19, Ottawa, 1983

[71] Wood S.R., 1992. Tooth wear and the sexual division of labour in an Inuit population. MA thesis, Simon Fraser University, Canada, 1992

[72] Marsh D.B., The stone winter houses of the Sadlermiut. The Beaver, 1976, 307, 36-39

[73] Mathiassen T., Archaeology of the Central Eskimos part I: descriptive part. Report of the Fifth Thule Ex- pedition 1921-24 vol. 4, Copenhagen, 1927

[74] Stewart K.M., Stewart F.L., Coupland G., Boardwalk northern northwest coast Canada - a new face to an old site. Canadian Journal of Archaeology, 2009, 33, 205-233

[75] Beynon A.D., Replication technique for studying microstructure in fossil enamel. Scanning Microscopy, 1987, 1, 663-669.

[76] Conover W.J., Iman R.L., Rank transformations as a bridge between parametric and nonparametric statistics. American Statistician, 1981, 35, 124-129

[77] Cook R.J., Farewell V.T., Multiplicity considerations in the design and analysis of clinical trials. Journal of the Royal Statistical Society, Series A, 1996, 159, 93-110

[78] Henry A.G., Brooks A.S., Piperno D.R., Microfossils in calculus demonstrate consumption of plants and cooked foods in Neanderthal diets (Shanidar III Iraq; Spy I and II Belgium). Proceedings of the National Academy of Sciences, 2010, 108, 486-491 